\title{
OCORRÊNCIA DE BUPRESTÍDEOS (COLEOPTERA) EM VEGETAÇÃO DE CERRADO, NO MUNICÍPIO DE SANTO ANTÔNIO DO LEVERGER, MT
}

\author{
Aquírya Pinheiro ${ }^{1}$ \\ Alberto Dorval² \\ Marcelo Dias de Souza ${ }^{3}$ \\ Diego Arcanjo do Nascimento ${ }^{1}$ \\ Lilian Guimarães de Favare ${ }^{4}$ \\ Josamar Gomes da Silva Junior ${ }^{5}$
}

\section{INTRODUÇÃO}

Os coleópteros são dominantes nos trópicos, esta ordem possui diversas espécies pragas de muita importância por causar danos no setor florestal, sobretudo espécies da família busprestidae. Para o controle de buprestídeos atualmente somente o controle cultural é eficiente para reduzir as populações dessas coleobrocas, este controle é realizado por meio de catação manual dos insetos adultos. Atualmente para o controle de buprestídeos, apenas o controle por meio de catação manual dos insetos adultos é efetivo. O estudo de meios de controle natural reguladores destas populações é desconhecido (GRAY, 1972; VICHIATO et al., 2014).

A família Buprestidae é composta por 400 gêneros e 15.000 espécies, cujo agrupamento é distribuído em 4 subfamílias: Schizopodinae, Julodinae, Buprestinae e Agrilinae. Devido ao ciclo dos buprestídeos ser longo, para o manejo é de extrema importância à realização do monitoramento periódico ao longo do ano todo, para uma possível constatação do começo e evolução das infes-

1 Bolsista Capes pelo Programa de PPG em Ciências Florestais e Ambientais, UFMT.

2 Prof. Dr. na Faculdade de Engenharia Florestal, Universidade Federal de Mato Grosso, UFMT.

3 Prof. Dr. da Faculdade de Engenharia Ambiental, Universidade de Cuiabá - UNIC.

4 Bolsista do Programa Nacional de Pós-Doutorado (Capes), pelo Programa de PPG em Ciências Florestais e Ambientais da Universidade Federal de Mato Grosso-PPGCFA/UFMT.

5 Mestre em Ciências Florestais e Ambientais pela Universidade Federal de Mato Grosso, UFMT. 
tações, assim possibilitando a identificação e quantificação das árvores atacadas (COSTA LIMA, 1953; MARINONI et al., 2001; DE NADAI, 2014).

Os Buprestídeos estão entre os principais besouros desfolhadores de eucalipto no Brasil por atacarem as folhas novas, roerem os galhos tenros e deceparem o ponteiro principal de espécies arbóreas em plantios comerciais (ANJOS e MAJER, 2003).

Tal evidência torna indispensável o monitoramento de insetos-pragas no setor florestal, afim de que se obtenham informações que possam ser utilizadas para a implantação de programas de manejo integrado de pragas, possibilitando a minimização dos custos de produção através de diminuição de danos futuros (SILVA PAZ et al., 2008).

Diante da relevância do tema, a importância de amostrar a diversidade de besouros da família Buprestidae com armadilhas etanólicas em um fragmento florestal no município de Santo Antônio de Leverger, MT expressa a contribuição científica para a ciência e a sociedade mato-grossense.

\section{DELINEAMENTO EXPERIMENTAL}

O estudo foi realizado na Área de Reserva Legal (ARL) do Instituto Federal de Educação Ciência e Tecnologia de Mato Grosso (IFMT), campus São Vicente, área de 192,00 ha, município de Santo Antônio do Leverger, com localização geográfica $15^{\circ} 49^{\prime} 21,42^{\prime \prime}$ S e $55^{\circ} 25^{\prime} 06,36^{\prime \prime} \mathrm{W}$, e altitude de $750 \mathrm{~m}$ acima do nível do mar, clima classificado por Thornthwaite (1948) como subúmido e com vegetação de cerrado.

\section{Método de coleta}

No total foram instaladas 25 armadilhas aéreas modelo escolitídeo - Curitiba iscadas com etanol a $70 \%$, dispostas aleatoriamente no ambiente. As amostragens foram quinzenais, de Maio/2016 à Abril/2017, totalizando 24 coletas. A identificação do material entomológico foi realizada por Prof. Dr. Germano H. Rosado Neto, do Departamento de Zoologia, da Universidade Federal do Paraná. 
Foram realizados estudos qualitativos, quantitativos e de flutuação populacional em relação a possível influência dos fatores abióticos, precipitação pluviométrica e temperatura média sobre as espécies estudadas.

\section{RESULTADOS E DISCUSSÃO}

Foram coletados 46 indivíduos pertencem à família Buprestidae, sendo 23 do gênero Chrysobothris (Erschscholtz, 1829) e 23 ao gênero Actenodes (Dejean, 1833). As espécies identificadas foram: Chrysobothris carbunculifer (Théry, 1911), Actenodes nobilis (Linnaeus, 1758) e Chrysobothris sp. (Tabela 1).

\begin{tabular}{ccc}
\hline Espécie & Q. indivíduos & Freq. \% \\
\hline Chrysobothris carbunculifer & 20 & 45,5 \\
\hline Actenodes nobilis & 23 & 50,0 \\
\hline Chrysobothris sp & 3 & 6,5 \\
\hline Total & 46 & 100 \\
\hline
\end{tabular}

Tabela 1. Quantidades de indivíduos coletados em armadilhas aéreas instaladas em área de reserva legal do IFMT, campus São Vicente.

A. nobilis foi a espécie que ocorreu com maior frequência (50\%), seguida por C. carbunculifer (45,5\%) e Chrysobothris sp. com apenas (6,5\%). Wolda (1988) associa a composição das comunidades de buprestídeos à quantidade e variedade de massa vegetal disponível, sobretudo de partes florais e foliares.

No Brasil foram realizados registros sobre a ocorrência apenas da espécie $A$. nobilis, nos estados do Amazonas e São Paulo (MANN 1912; SEMA, 2015). Portanto, trata-se do primeiro registro sobre a ocorrência das espécies $A$. nobilis e $C$. carbunculifer, no município de Santo Antônio do Leverger, no estado de Mato Grosso.

Esse grupo de insetos, aparentemente, tem uma forte relação com a precipitação, pois à medida que as chuvas aumentam, sua densidade populacional apresentou um decréscimo (Figura 1). Os meses do período seco podem coincidir com o período de emergências dos novos indivíduos adultos, com o período 
de acasalamento e de seleção de novos hospedeiros. Enquanto o período chuvoso, pelo fato de diminuir o número de indivíduos adultos coletados, pode estar relacionado como período de abertura de galerias nos novos hospedeiros, com o estágio larval e pupal das espécies estudadas. Segundo Anjos et al. (2004); De Nadai (2005; 2012), em plantios de eucalipto, este comportamento acontece inversamente, pois as maiores ocorrências de adultos se iniciam após as primeiras chuvas, entre os meses de dezembro e fevereiro na região.

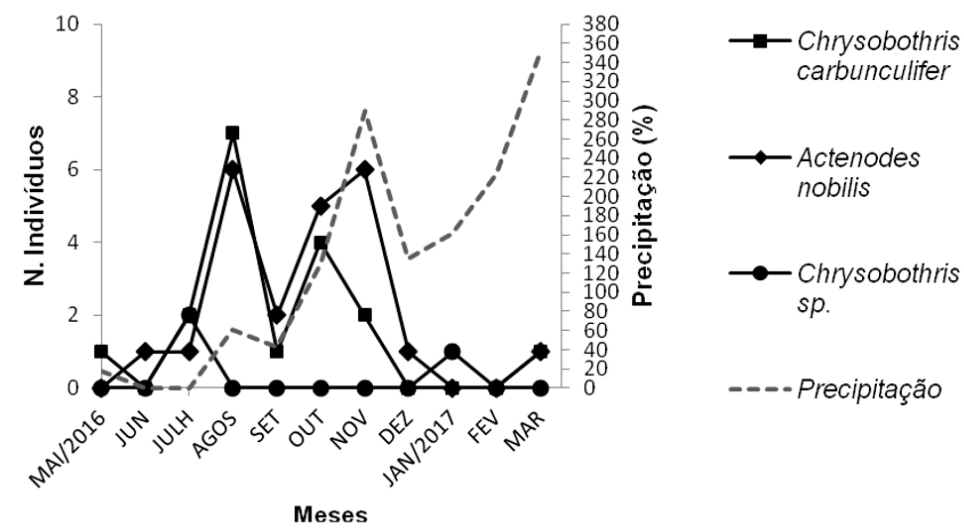

Figura 1. Flutuação populacional de buprestídeos em função da precipitação pluviométrica $(\mathrm{mm})$.

Os picos populacionais e as ocorrências mínimas de insetos ocorreram praticamente contendo a mesma temperatura, assim demonstra que temperatura não é um fator abiótico favorável às espécies coletadas, sendo que sua ocorrência está associada a outros fatores, como umidade relativa e precipitação (Figura 2). Balachowsky (1962) afirma que a postura não se inicia sem que a temperatura atinja $26^{\circ} \mathrm{C}$, se finda aos $40^{\circ} \mathrm{C}$ e tem um óptimo dos 28 aos $34^{\circ} \mathrm{C}$. 


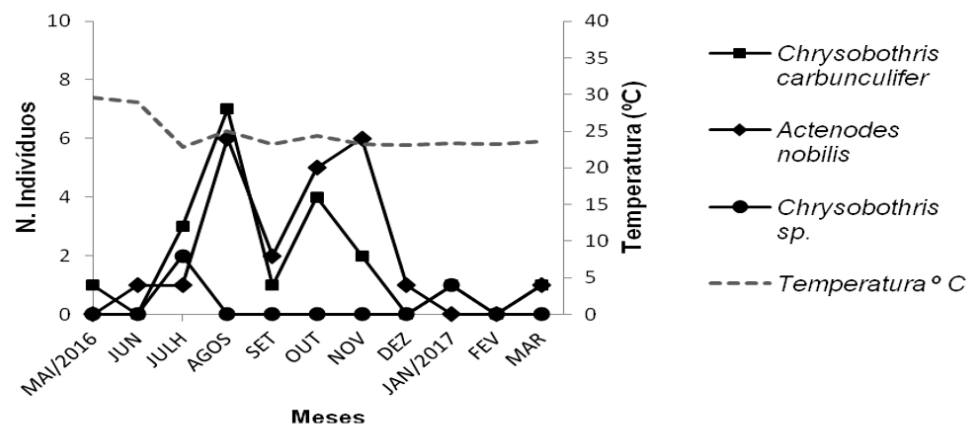

Figura 2. Flutuação populacional de buprestídeos em função da temperatura $\left({ }^{\circ} \mathrm{C}\right)$.

\section{CONSIDERAÇÕES FINAIS}

Visando o Projeto de Manejo Florestal é recomendável a intervenção nos períodos de estiagem, pois este processo pode acarretar estresse nos vegetais e assim propiciar o ataque de buprestídeos nas árvores.

\section{REFERÊNCIAS}

ANJOS, N. \& MAJER, J. D. Leaf-eating beetles in Brazilian eucalypt plantations. School of Environmental Biology, Australia. n 23, p.10-11. 2003.

ANJOS, N. et al. Ocorrência de buprestídeos em eucaliptais de Minas Gerais. In: CONGRESSO BRASILEIRO DE ENTOMOLOGIA, 20., 2004, Gramado. Anais... Gramado: Universidade Federal de Santa Maria, 2004, p. 453

BALACHOWSKY, A. S. Entomologie appliquée à l’agriculture. Tome I. Coléoptères. Vol I, 6a ed., Masson et Cie Editeurs, Paris, 1962.

COSTA LIMA, A. INSETOS DO BRASIL: COLEÓPTEROS 2.a PARTE. Escola nacional de agronomia série didática n. 10, 1953.

DE NADAI, J. Biologia de Lampetis nigerrima (Kerremans, 1897) (Coleoptera: Buprestidae) em eucalipto. Dissertação (Mestrado em Entomologia) Universidade Federal de Viçosa, 2005, 44p.

DE NADAI, J. Morfologia, consequências do ataque de lampetis nigerrima (kerremans, 1897) (Coleoptera: Buprestidae) e poda de correção em clone de eucalipto. Tese de Doutorado. Minas Gerais, 2008.

DE NADAI, J. Ataque de lampetis nigerrima (kerremans, 1897) (Coleoptera: Bu- 
prestidae) e poda de formação em clone de eucalipto. Ciência Florestal, Santa Maria, v. 22, n. 3, p. 519-531, jul.set., 2012.

GRAY, B. Economic tropical forest entomology. Annual Review Entomology, v. 17, p. 313-335, 1972.

MANN, W. M. M. The Stanford expedition to Brazil: List of histeridz and buprestid. Psyche,19:118-122, 1912.

MARINONI, R. C.; GANHO, N. G.; MONNÉ, M. L.; MERMUDES, J. R. Hábitos alimentares em Coleoptera (Insecta). São Paulo: Holos Editora, 2001. 63p.

SEMA. (2015). Plano de Manejo Integrado das Unidades de Conservação Reserva Biológica e Estação Ecológica Mogi-Guaçu SP. Instituto Florestal. ISBN: 978-857523-061-9.

SILVA PAZ, J. K. et al. Monitoramento de coleobrocas associadas à mangueira no município José de Freitas, estado do Piauí. Revista Brasileira de Fruticultura, 30(2): 348-355, 2008.

THORNTHWAITE, C.W. (1948). An approach toward a rational classification of climate. Geographical Review, 38:55-94.

VICHIATO, M. R. M. Ocorrência de Euchroma gigantea (Coleoptera: Buprestidae) em Belo Horizonte, MG. Tecnol. \& Ciên. Agropec., João Pessoa, v.8, n.5, p.7-11, dez. 2014 | 7.

WOLDA, H. Insect seasonality. Why Annual Review of Ecology and Systematics, Palo Alto, v. 19, p. 1-18, 1988. 